CZASOPISMO INŻYNIERII LADDOWEJ, ŚRODOWISKA I ARCHITEKTURY JOURNAL OF CIVIL ENGINEERING, ENVIRONMENT AND ARCHITECTURE

JCEEA, t. XXXII, z. 62 (4/15), październik-grudzień 2015, s. 347-356

\author{
Grzegorz OLENIACZ ${ }^{1}$ \\ Izabela SKRZYPCZAK ${ }^{2}$ \\ Lidia BUDA-OŻóG ${ }^{3}$ \\ Janusz KOGUT $^{4}$
}

\title{
BADANIA PRZEMIESZCZEŃ STALOWYCH WIEŻ TELEKOMUNIKACYJNYCH O RÓŻNEJ KONSTRUKCJI TRZONU
}

\begin{abstract}
Stan techniczny i bezpieczeństwo obiektów budowlanych zależy między innymi od określenia odchyłek geometrycznych całej konstrukcji oraz jej poszczególnych elementów i odniesienia ich do zdefiniowanych w zaleceniach normowych wartości dopuszczalnych. W artykule zaprezentowano badania przemieszczeń dla trzech wież telekomunikacyjnych o różnej konstrukcji, a otrzymane wartości porównano z zaleceniami normowymi. Graniczne wartości przemieszczeń zaproponowane przez PN-B-03204 są dla wszystkich analizowanych przypadków spełnione. Aktualna norma Eurokod 3 nie podaje wartości graniczny przemieszczeń wierzchołka, uzależniając je od zaleceń użytkownika. Użytkownik zobowiązany jest więc do przeprowadzenia rektyfikacji i spełnienia wymogów normowych. Otrzymane wyniki potwierdziły badania stalowych wież antenowych. Analizując otrzymane wyniki pomiarów przemieszczeń stwierdzono, że przy umiarkowanym nasłonecznieniu i braku wiatru przemieszczenia wierzchołkowego odcinka nie przekraczają wartości granicznych zalecanych dla tego typu konstrukcji, duże nasłonecznienie i temperatury przekraczające 30 stopni Celsjusza zwiększają przemieszczenia badanych konstrukcji, ponadto wieże stalowe o konstrukcji rurowej charakteryzują się małą odpornością na rozszerzalność termiczną.
\end{abstract}

Słowa kluczowe: wieże telekomunikacyjne, badania, pomiary, przemieszczenia

\section{Wstęp}

Pomiary przemieszczeń i odkształceń obiektów są niezwykle ważne w celu określenia trwałości i bezpieczeństwa techniczno-budowlanego oraz użytko-

${ }^{1}$ Autor do korespondencji: Grzegorz Oleniacz, Politechnika Rzeszowska, ul. Poznańska 2, 35-211 Rzeszów,oleniacz@prz.edu.pl

${ }^{2}$ Izabela Skrzypczak, Politechnika Rzeszowska, ul. Poznańska 2, 35-211 Rzeszów, izas@prz.edu.pl

${ }^{3}$ Lidia Buda-Ożóg, Politechnika Rzeszowska, ul. Poznańska 2, 35-211 Rzeszów, lida@prz.edu.pl

${ }^{4}$ Janusz Kogut, Politechnika Krakowska, ul. Warszawska 24, 30-155 Kraków, jkogut@pk.edu.pl 
wego budowli inżynierskich. Stalowe wieże i maszty antenowe muszą spełnić nie tylko wymagania i zalecenia Instrukcji ER-01 „Eksploatacja wież i masztów" [1], ale również ze względu na swoją konstrukcję powinny być wykonane zgodnie $\mathrm{z}$ postanowieniami i zaleceniami odpowiednich norm branżowych w odniesieniu do konstrukcji stalowych [2,3], a ich odchyłki nie powinny przekraczać wartości granicznych podanych w tychże normatywach.

\section{Normy branżowe oraz wymagania techniczne}

Zasadnicze wymagania techniczne dotyczące terminów i sytuacji, w których należy dokonać badań diagnostycznych oraz zakres wymaganej analizy zostały określone w Instrukcji ER-01. Eksploatacja wież i masztów [1].

Zgodnie z tą instrukcją należy przeprowadzać:

- inspekcje podstawowe oraz okresowe,

- naprawy bieżące oraz główne,

- pomiary i regulacje oraz okresowe konserwacje.

Inspekcja podstawowa to kontrola wewnętrzna wykonywana jeden lub dwa razy w roku lub w trybie doraźnym w przypadku huraganowego wiatru. Natomiast inspekcja okresowa to kontrola zewnętrzna, której częstotliwość uzależniona jest od kategorii wieży (por. [1]).

Zgodnie z wytycznymi Instrukcji ER-01 [1] odchylenia osi trzonu wieży od pionu większe od L/750 zalicza się do wad zagrażających bezpieczeństwu konstrukcji i wymagającej niezwłocznej naprawy, zaś odchylenia większe od L/1000 do wad pogarszających stan konstrukcji, których naprawę należy wykonać w ciągu roku.

Wg zaleceń PN-B-03204:2002. Konstrukcje stalowe. Wieże i maszty. Projektowanie wykonanie [2] wartości graniczne odkształceń należy ograniczyć do wartości podanych przez użytkowników wieży w zależności od ich przeznaczenia. Jeżeli nie uzgodniono inaczej, to należy przyjmować następujące wartości graniczne:

- przemieszczenie wierzchołka wieży lub masztu nie większe niż 1/100 całkowitej wysokości,

- przemieszczenie węzłów masztu nie większe niż 1/100 odległości węzła od podstawy masztu,

- maksymalne ugięcie przęseł masztu od linii łączącej węzły nie większe niż 1/250 rozpiętości przęsła,

- ugięcie skratowania nie większe niż $1 / 200$ długości pręta.

PN-EN 1993-3-1:2008 Eurokod 3: Projektowanie konstrukcji stalowych. Część 3-1: Wieże, maszty i kominy - Wieże i maszty [3], w swoim załączniku B podaje, że kryteria użytkowalności tj. przemieszczenia i obroty są definiowane w specyfikacji projektowej przez zamawiającego i nie podaje granicznych wartości odniesienia. 
Badania przemieszczeń metodami geodezyjnymi należy zaś wykonywać zgodnie z wymogami branżowymi w odniesieniu do prac geodezyjnych, a więc z:

- Instrukcją techniczną G-3. Geodezyjna obsługa inwestycji. Wyd. II Warszawa 1980 [4], oraz

- Rozporządzeniem Ministra Gospodarki Przestrzennej i Budownictwa z dnia 21 lutego 1995 r. w sprawie rodzaju i zakresu opracowań geodezyjno-kartograficznych oraz czynności geodezyjnych obowiązujących w budownictwie. Dz.U. nr 25 z dnia 13 marca 1995 r. poz. 133 [5].

\section{Pomiary geodezyjne oraz charakterystyka badanych wież}

\subsection{Przeprowadzone badania}

Przeprowadzone wielokrotne pomiary geodezyjne pozwalają wyznaczyć nie tylko wielkość przemieszczeń, ale również przebieg trajektorii przemieszczeń. W analizowanych przypadkach obserwacji podlegały nie tylko trzony wież antenowych, ale głównie ich wierzchołki. Dokonywano:

- pojedyncze kątowe wcięcia wprzód,

- pomiar bazy dalmierzem elektronicznym dwukrotnie w obu kierunkach,

- pomiar kątów w odstępach około 1,5 do 2 godzin, w jednej serii, w dwóch położeniach lunety, jednocześnie z obu końców bazy.

Przeprowadzone obliczenia obejmowały:

-wyznaczenie współrzędnych w układzie lokalnym, w przybliżeniu zorientowanym do kierunku północy,

-obliczenie średniego błędu wyznaczenia współrzędnych, przy założeniu średniego błędu długości bazy $-\mathrm{d}$ : $\mathrm{m}_{\mathrm{d}}= \pm 1,5 \mathrm{~cm}$ oraz średniego błędu pomiaru kątów $-\alpha$ i $\beta: m_{\alpha}=m_{\beta}=30^{c c}$ (we wzorze (1) błąd pomiaru kąta podaje się w mierze łukowej).

Do określenia błędu wyznaczenia współrzędnych wykorzystano wzór (1) zaproponowany przez T. Lazzarini [6]:

$$
m_{P}^{2}=\frac{d^{2}}{\sin ^{4}(\alpha+\beta)}\left(\sin ^{2} \beta \cdot m_{\alpha}^{2}+\sin ^{2} \alpha \cdot m_{\beta}^{2}\right)+\frac{\sin ^{2} \beta \cdot m_{d}^{2}}{\sin ^{2}(\alpha+\beta)}
$$

\subsection{Charakterystyka badanych wież}

Przedmiotem badań były trzy wieże antenowe o różnej wysokości od 40 do $55 \mathrm{~m}$. Konstrukcje badanych wież przedstawiono na poniższych fotografiach i rysunkach, wraz z wynikami badań omówionymi w dalszej części:

$>$ Wieża GSM nr 1:

- konstrukcja stalowa, kratownicowa o podstawie kwadratu,

- wysokość 50m. 


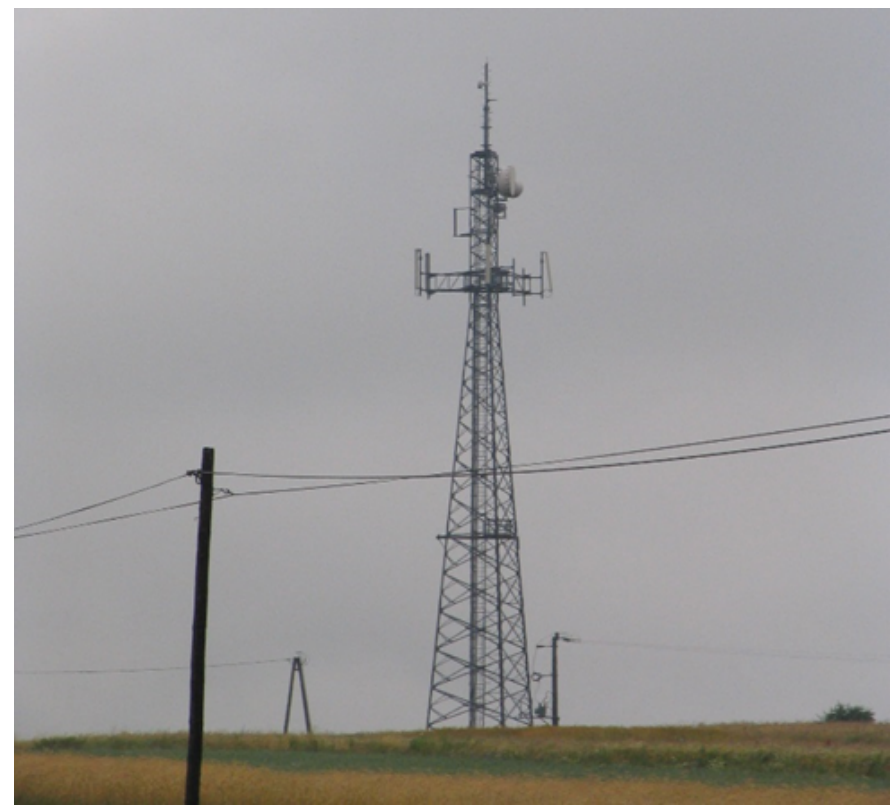

Rys. 1. Wieża GSM nr 1

Fig. 1. GSM telecommunication tower No.1

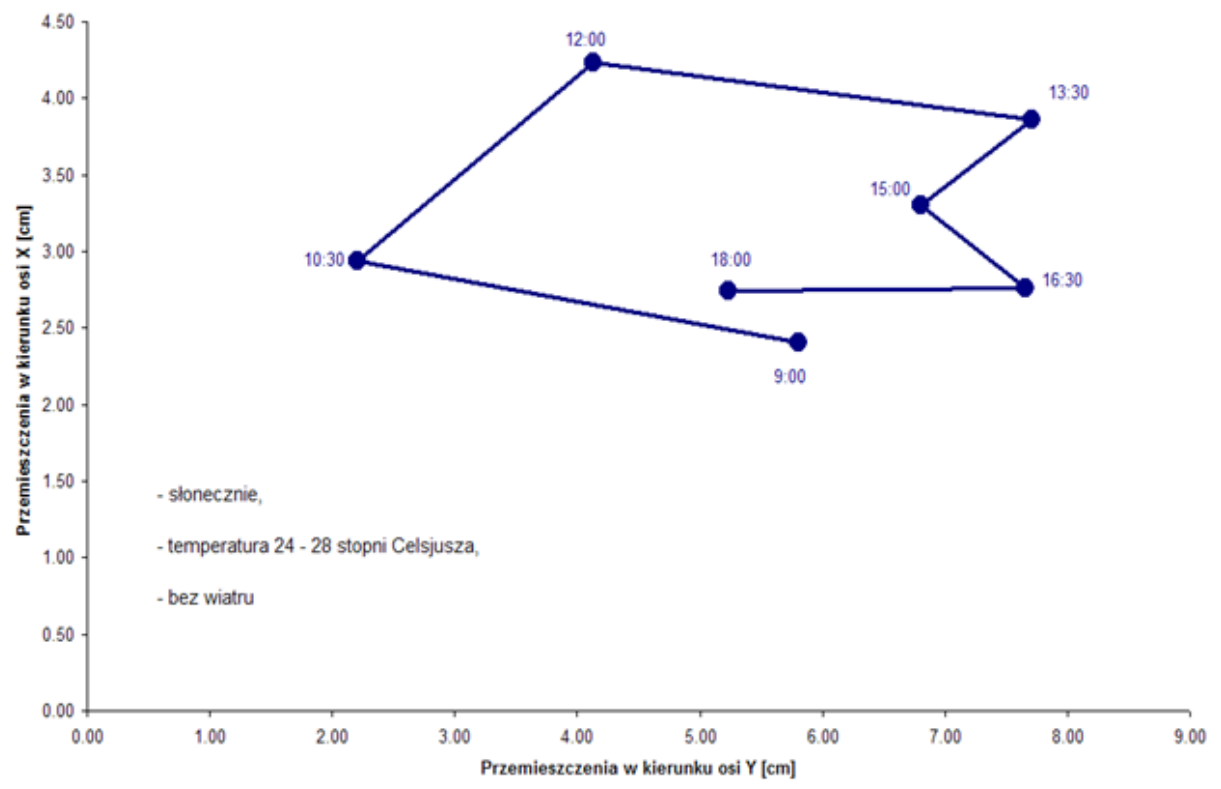

Rys. 2. Obliczone przemieszczenia wierzchołka wieży $\mathrm{nr} 1$

Fig. 2. The displacements of the top as calculated for the tower No. 1 


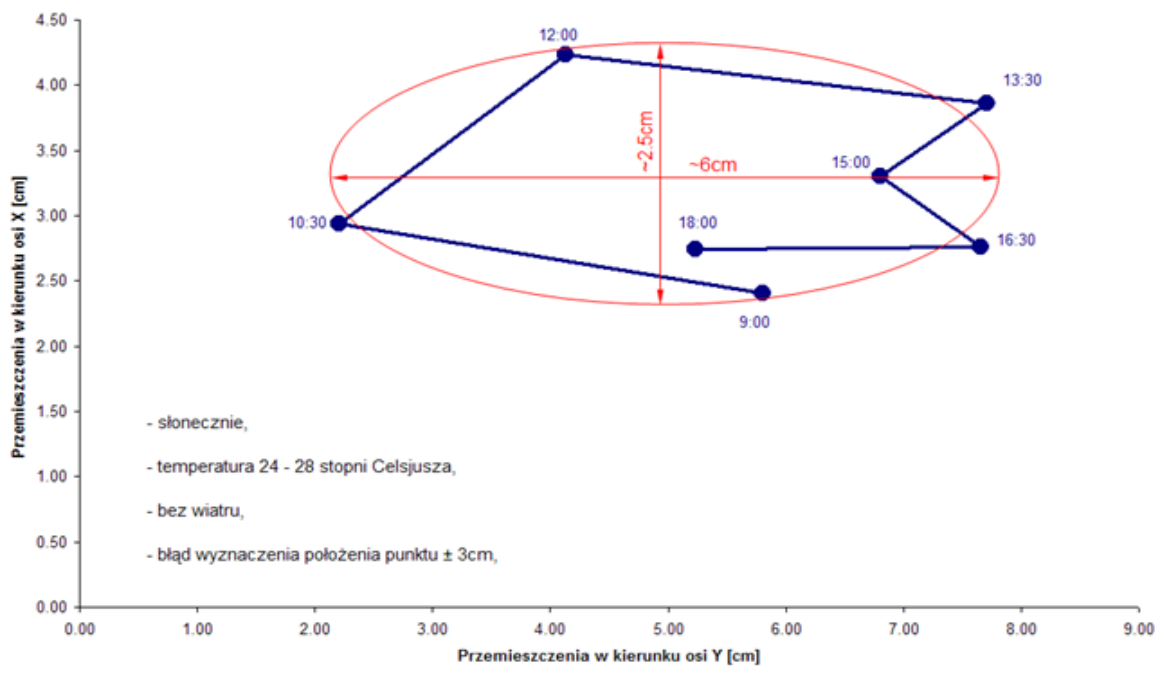

Rys. 3. Trajektoria przemieszczeń wierzchołka wieży nr 1

Fig. 3. Trajectory of the displacement of the top of tower No. 1

Wieża GSM nr 2:

- konstrukcja stalowa, kratownicowa o podstawie trójkąta,

- wysokość 55m.

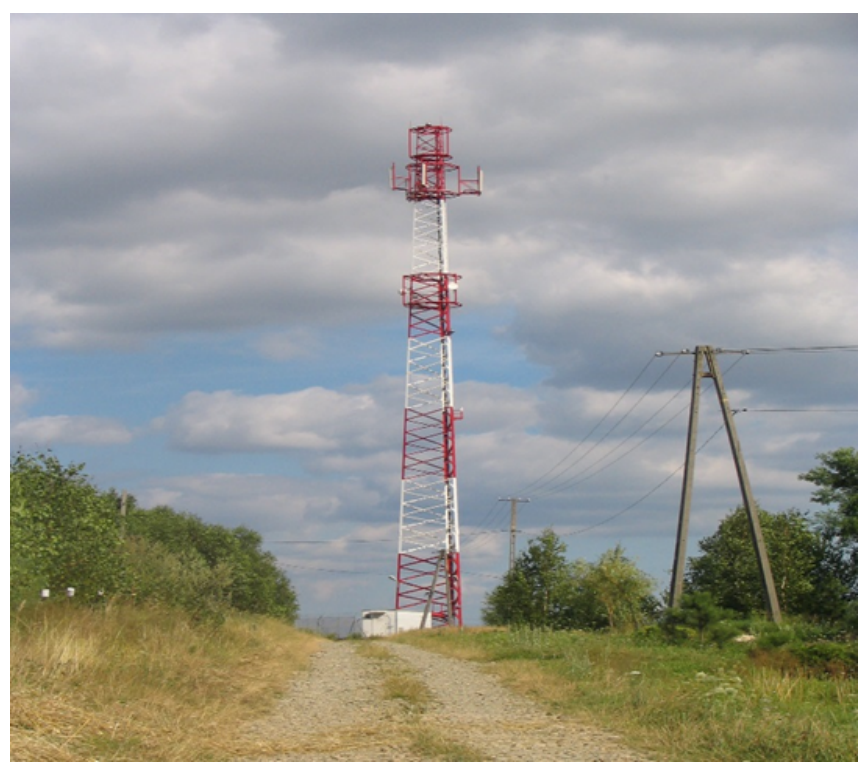

Rys. 4. Wieża GSM nr 2

Fig. 4. GSM telecommunication Tower No. 2 


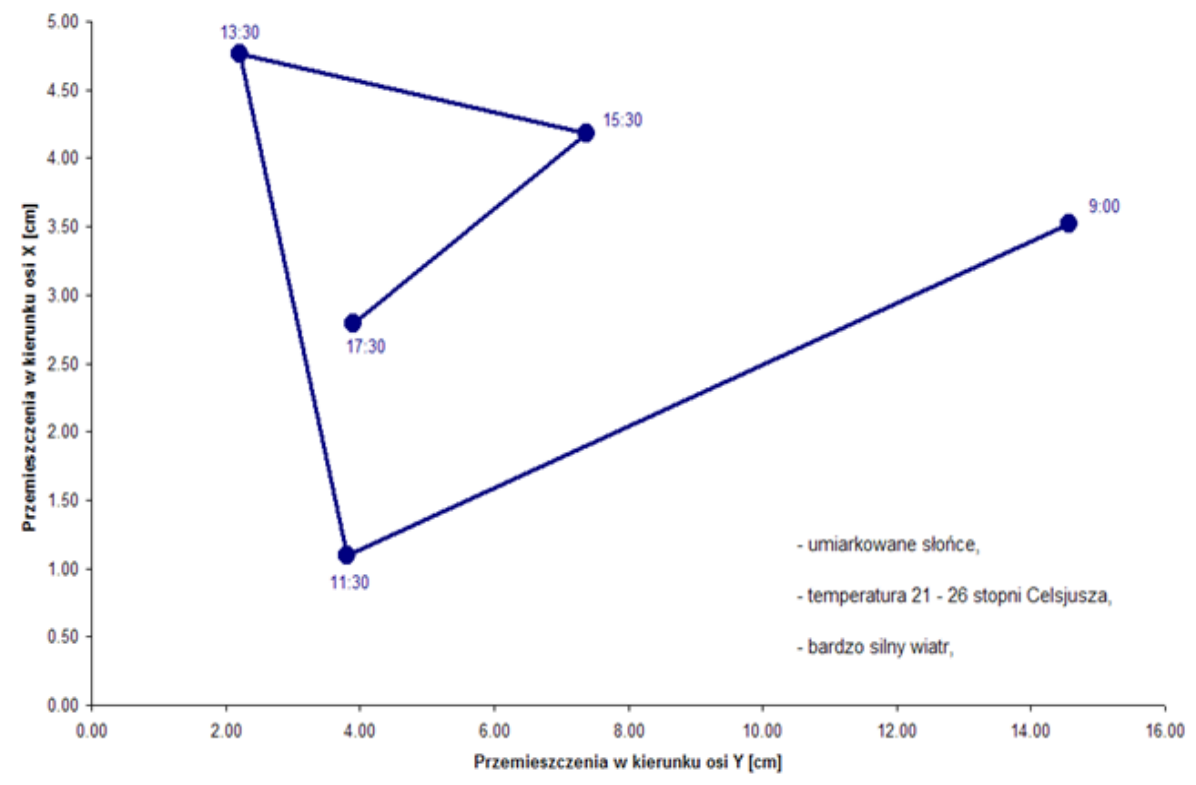

Rys. 5. Obliczone przemieszczenia wierzchołka wieży $\mathrm{nr} 2$

Fig. 5. The displacements of the top as calculated for the tower No. 2

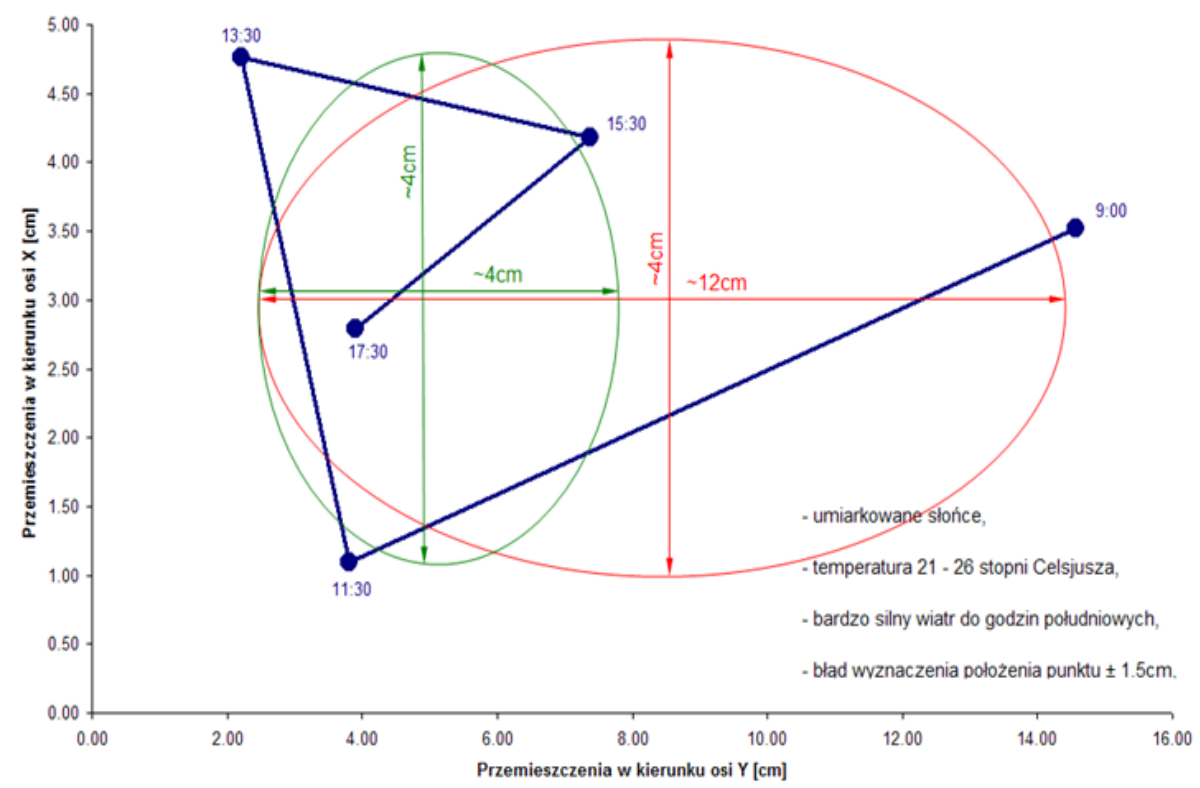

Rys. 6. Trajektoria przemieszczeń wierzchołka wieży $\mathrm{nr} 2$

Fig. 6. Trajectory of the displacement of the top of tower No. 2 
Wieża GSM nr 3:

- konstrukcja stalowa o konstrukcji rurowej,

- wysokość 40m.

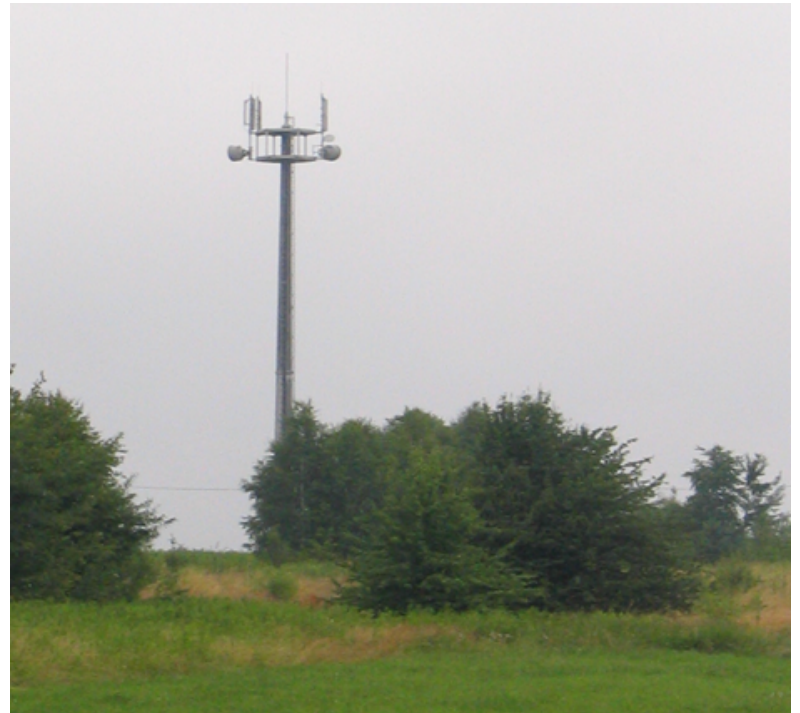

Rys. 7. Wieża GSM nr 3

Fig. 7. GSM telecommunication Tower No. 3

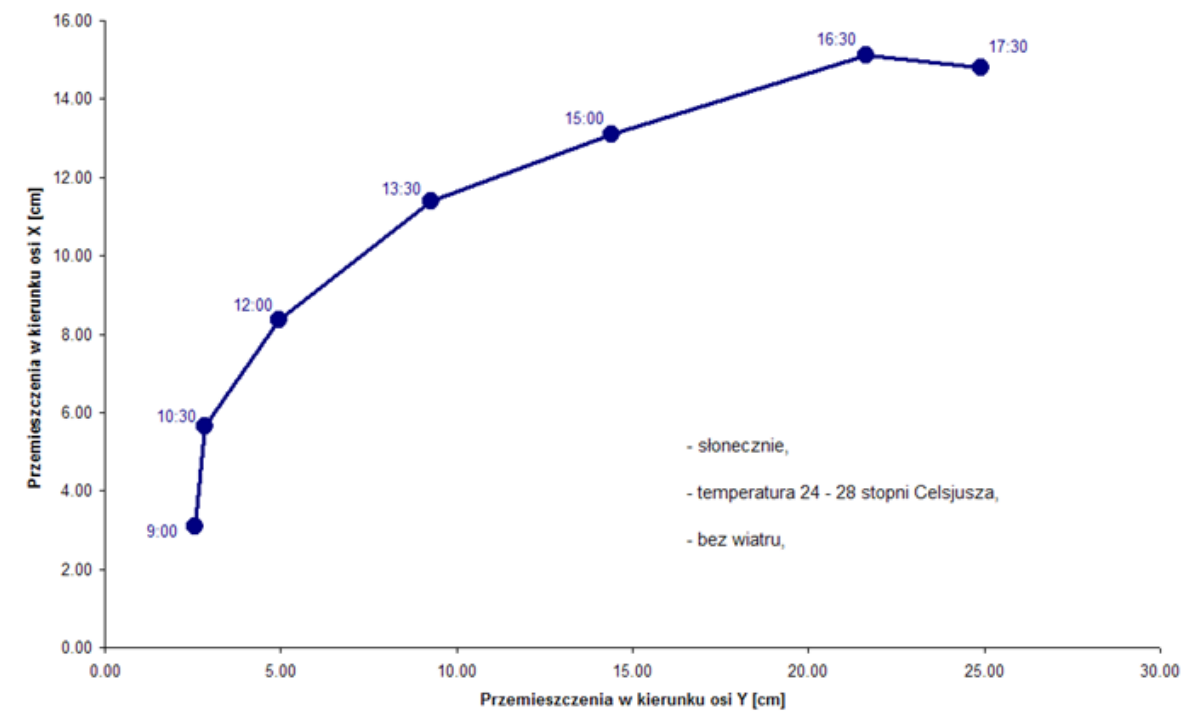

Rys. 8. Obliczone przemieszczenia wierzchołka wieży $\mathrm{nr} 3$

Fig. 8. The displacements of the top as calculated for the tower No. 3 


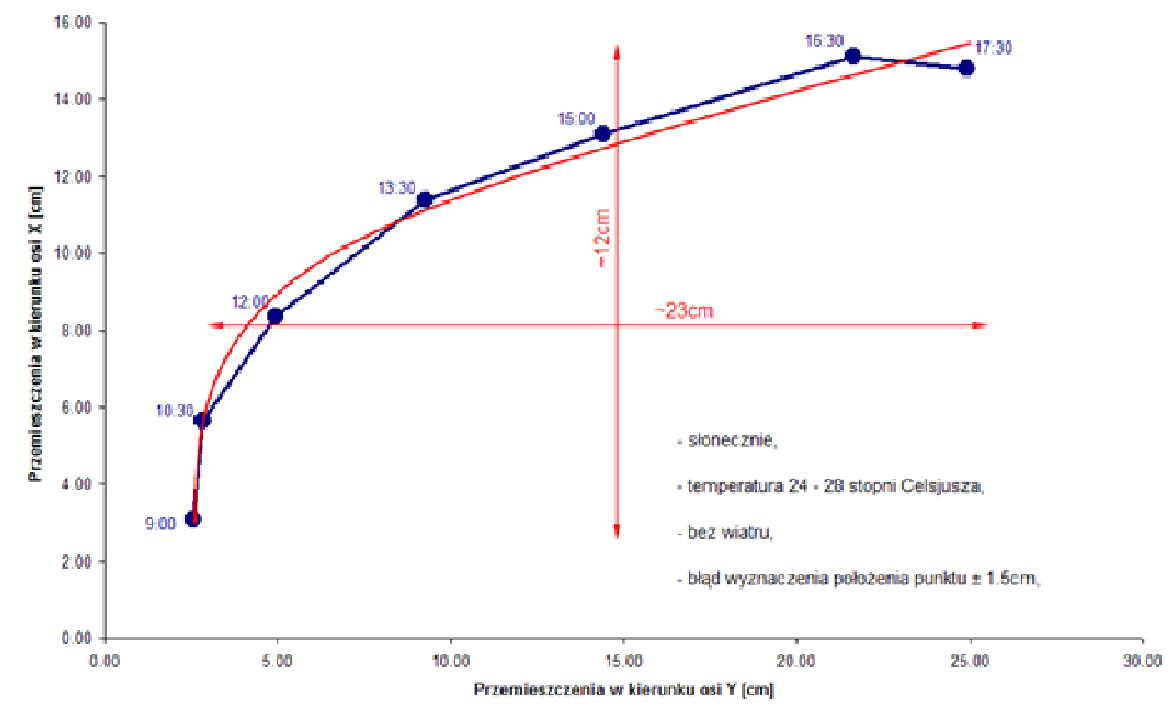

Rys. 9. Trajektoria przemieszczeń wierzchołka wieży $\mathrm{nr} 3$

Fig. 9. Trajectory of the displacement of the top of tower No. 3

Tabela 1. Pomiar wychyleń wierzchołkowego odcinka wież

Table 1 . The measurements of deflection of the tip section of the analysed towers

\begin{tabular}{|c|c|c|c|c|c|}
\hline \multirow{2}{*}{$\begin{array}{l}\text { Wieża } \\
\text { numer }\end{array}$} & \multirow{2}{*}{$\begin{array}{c}\text { Wysokość } \\
\text { Konstrukcyjna } \\
{[\mathrm{m}]}\end{array}$} & \multirow{2}{*}{$\begin{array}{c}\text { Wypadkowa } \\
\text { przemieszczenia } \\
\text { wierzchołka wieży } \\
{[\mathrm{mm}]}\end{array}$} & \multirow{2}{*}{$\begin{array}{c}\text { Obliczone war- } \\
\text { tości } \\
\text { wychylenia } \\
\text { wypadkowego } \\
{[\mathrm{mm}]}\end{array}$} & \multicolumn{2}{|c|}{$\begin{array}{c}\text { Wartości dopuszczalne } \\
\text { wychylenia [mm] }\end{array}$} \\
\hline & & & & $\begin{array}{l}\text { PN-B- } \\
03204: \\
\text { L/100 }\end{array}$ & $\begin{array}{c}\text { Instrukcja } \\
\text { ER-01 } \\
\text { L/1000 } \\
\end{array}$ \\
\hline 1 & 50 & 65 & 32 & 500 & 50 \\
\hline 2 & 55 & $56\left[126^{*}\right]$ & 28 & 550 & 55 \\
\hline 3 & 40 & 173 & 86 & 400 & 40 \\
\hline
\end{tabular}

Pomierzone wychylenia wierzchołkowego odcinka przekraczają normowe wartości dopuszczalne zalecane przez Instrukcję ER-01 (por. Tab. 1). Graniczne wartości przemieszczeń zaproponowane przez PN-B-03204 są dla wszystkich analizowanych przypadków całkowicie spełnione. Aktualnie zalecana norma Eurokod 3 nie podaje wartości granicznych przemieszczeń wierzchołka, uzależniając je od wymagań użytkownika wieży.

Użytkownik zobowiązany jest więc do przeprowadzenia rektyfikacji i spełnienia wymogów normowych. Otrzymane wyniki potwierdziły badania przeprowadzone przez B. Wichtowskiego w odniesieniu do stalowych wież antenowych (por. [7]). 


\section{Uwagi końcowe}

Analizując otrzymane wyniki pomiarów przemieszczeń można stwierdzić, że:

- przy umiarkowanym nasłonecznieniu i braku wiatru przemieszczenia wierzchołkowego odcinka wież nie przekraczają wartości granicznych zalecanych dla tego typu konstrukcji,

- duże nasłonecznienie i temperatury przekraczające 30 stopni Celsjusza zwiększają przemieszczenia badanych konstrukcji,

- wieże stalowe o konstrukcji rurowej charakteryzują się małą odpornością na rozszerzalność termiczną (małą bezwładnością termiczną).

\section{Literatura}

[1] Instrukcja ER-01. Eksploatacja wież i masztów. Załącznik do zarządzenia nr 31 Prezesa Zarządu TP S.A. z dnia 30.06.1994, W-wa 1994

[2] PN-B-03204:2002. Konstrukcje stalowe. Wieże i maszty. Projektowanie wykonanie.

[3] PN-EN 1993-3-1:2008 Eurokod 3: Projektowanie konstrukcji stalowych. Część 3-1: Wieże, maszty i kominy. Wieże i maszty.

[4] Prawo geodezyjne i kartograficzne. DzU z dnia 21 listopada 2000 r. nr 100. Poz. 1086. Obwieszczenie Ministra Rozwoju Regionalnego i Budownictwa z dnia 24 października 2000 r. w sprawie ogłoszenia jednolitego tekstu ustawy - Prawo geodezyjne i kartograficzne.

[5] Rozporządzenie Ministra Gospodarki Przestrzennej i Budownictwa z dnia 21 lutego 1995 r. w sprawie rodzaju i zakresu opracowań geodezyjno-kartograficznych oraz czynności geodezyjnych obowiązujących w budownictwie. DzU nr 25 z dnia 13 marca 1995 r. poz. 133.

[6] Lazzarini T.: Geodezja, Geodezyjna osnowa szczegółowa, PPWK, Warszawa 1990

[7] Wichtowski B.: Rektyfikacja stalowych wież antenowych na podstawie inspekcji okresowych, XXIII KN-T, Awarie budowlane 2007, Szczecin-Międzyzdroje 23-26 maja 2007, str. 665-672

\section{SURVEYING OF THE DISPLACEMENTS OF TELECOMMUNICATION STEEL TOWERS OF VARIOUS STRUCTURAL DESIGN}

\footnotetext{
S u m m a r y

Technical conditions and the safety of steel structures depends, among other things, on determination of the geometrical deflections of the whole structure and its individual elements, and relate them to the values defined by the code limits. The paper presents the measurement of displacements for three selected telecommunication towers of various structural design. The results of survey are compared with those provided by the relevant codes. The limit values of displacements proposed by the PN-B-03204 are in all analyzed cases fulfilled. Currently, the recommended standard Eurocode 3 does not specify a limit value of displacements for the top of masts and towers. It makes them dependent on the recommendations of the tower user. The user is therefore obliged to carry out rectification and meet the requirements of code.
} 
The analysis of the displacement measurements showed that: with a moderate sun exposure and no wind, the displacement of the tip section of the towers do not exceed the limit values recommended for this type of steel structures, a significant sun exposure and temperatures exceeding 30 degrees of centigrade increase the displacement of the surveyed steel structures, and finally tubular steel towers have a low resistance to the thermal expansion.

Keywords: telecommunication steel towers, survey, displacements

Przestano do redakcji:30.05.2015

Przyjęto do druku:10.01.2016

DOI: $10.7862 / \mathrm{rb} .2015 .200$ 